\title{
Insufficient Job Control among Gastroenterology Trainees: Time to Focus on the Science
}

\section{To the Editor:}

Nam et al. ${ }^{1}$ undertook a remarkable study highlighting job stress in the field of gastroenterology. Among their findings, they noted that fellows demonstrated insufficient job control in relation to more senior professorial colleagues. ${ }^{1}$

The field of gastroenterology has been slow to catch up with advances in medical education. Hence, this finding is not a surprise. When we look into the science of learning and, more specifically, masterful learning, various facets are essential. Schumacher et al. ${ }^{2}$ described several including team relatedness, autonomy, and personalized learning. Even today, trainees demonstrate a lack of team relatedness and autonomy. If we as educators are true to ourselves, can we honestly admit to imparting these elements to junior members? Often, there is still a "them vs. us" culture, which hinders progression in the field. ${ }^{3}$ Furthermore, we all are aware that individuals during training achieve competency at different rates. We should recognize, therefore, the importance of personalized learning where content is tailored appropriately to needs of the individual in question and more specifically on areas they are less aware of. An additional facet of masterful learning is that of feedback-and, more importantly, the nature of feedback, delivered in a non-judgmental manner in a safe learning environment with the additional opportunity to give feedback to seniors.

If we continue to fall behind on the science of learning, we will continue to read studies that highlight job issues.

Conflicts of Interest

The author has no financial conflicts of interest.

Neel Sharma ${ }^{1,2}$

${ }^{1}$ Department of Gastroenterology, National University Health System, Singapore, ${ }^{2}$ Harvard Macy Institute, Boston, MA, USA

\section{REFERENCES}

1. Nam SJ, Chun HJ, Moon JS, et al. Job stress and job satisfaction among health-care workers of endoscopy units in Korea. Clin Endosc 2016;49:266272.

2. Schumacher DJ, Englander R, Carraccio C. Developing the master learner: applying learning theory to the learner, the teacher, and the learning environment. Acad Med 2013;88:1635-1645.

3. Limb M. "Them and us" attitude hinders trainees' leadership development [Internet]. London: BMJ Careers; c2014 [updated 2015 Dec 3; cited 2016 Aug 20]. Available from: http://careers.bmj.com/careers/ advice/\%E2\%80\%9CThem_and_us $\%$ E2\%80\%9D_attitude_hinders_ trainees\%E2\%80\%99_leadership_development.

Received: July 6, 2016 Accepted: July 8, 2016

Correspondence: Neel Sharma

Department of Gastroenterology, National University Health System, 1E Kent Ridge Road, 119228, Singapore

Tel: +65-91745985, Fax: +65-91745985, E-mail: sharma_neel@outlook.com

(cc) This is an Open Access article distributed under the terms of the Creative Commons Attribution Non-Commercial License (http://creativecommons.org/licenses/by$\mathrm{nc} / 3.0$ ) which permits unrestricted non-commercial use, distribution, and reproduction in any medium, provided the original work is properly cited. 


\section{RESPONSE}

Thank you for your interest in our study and your valuable comments.

This is the first Korean study evaluating job stress and satisfaction of endoscopic unit workers as a team. We hope this study will draw attention to job stress evaluation and management in the field of gastroenterology, even though our study population was too small to represent national endoscopic teams and analyze/adjust many cofactors affecting job stress.

We could identify major stressors of endoscopy unit workers and compare them according to the different job positions. Importantly, evaluation of job stress should not end with a temporary event. We need regular follow-up and re-evaluation of job stress and the working environment in endoscopy units. Appropriate follow-up intervals also need to be determined. More importantly, systematic interventions for managing disclosed stressors by job stress evaluation are critical, and this cannot be properly accomplished without support on both national and social levels. Individual efforts to intervene on stressors by enhancing coping strategies such as psychoeducation and meditation have a limited role and are not a fundamental solution. Some important suggestions can be found in the commentary of this article. ${ }^{1}$ We also propose a national survey of job stress of endoscopy units in Korea organized by an academic society such as the Society of Gastrointestinal Endoscopy.

Finally, as Dr. Neel Sharma mentioned, fellow is somewhat estranged group also in Korea. Recently, systematic improvement of educational and working environments was achieved for residents in Korean hospitals, but there is still no discussion regarding fellows. It is time to consider training and creating an educational environment that focuses on fellows. In this respect, team relatedness, autonomy, personalized learning, and feedback are important components to consider for improvement of the training system, as Dr. Sharma suggested.

Conflicts of Interest

The authors have no financial conflicts of interest.

Seung-Joo Nam ${ }^{1}$ and Hoon Jai Chun ${ }^{2}$

${ }^{1}$ Department of Internal Medicine, Kangwon National University School of Medicine, Chuncheon, ${ }^{2}$ Division of Gastroenterology and Hepatology, Department of Internal Medicine, Korea University College of Medicine, Seoul, Korea

\section{REFERENCE}

1. Yang YJ, Baik GH. Now, it is time to consider job stress in the field of gastroenterology. Clin Endosc 2016;49:209-211. 